\title{
Exploring the Perceptions of Staff tow ards Children and Young People Living in Community-based Children's Homes
}

G AVIN HERON A N D MONO CHAKR A B A R T I

University of Strathclyde, Scotland

Children's homes remain one of the most complex and emotive working environments in social work. Although the low level of qualifications amongst staff and the ongoing failures of the residential system are well documented (CCETSW, 1992; Dobson, 1998), there has been much less research on the staff's perceptions of children. This is perhaps surprising given that the way staff perceive children is likely to be crucial in understanding what actually goes on in community-based children's homes. The findings presented in this article are 
from one part of a doctoral study focusing on the perceptions of staff towards children, with particular reference to how they might shape the child-worker relationship. Interviews with residential staff were structured using the repertory grid technique and the data are presented in the form of a case study.

\section{A Changing Population}

Young people in children's homes are 'among the most damaged and disadvantaged in our society' (Berridge and Brodie, 1998: 119). Although poverty has remained a common experience for many of those entering the care system (Bebbington and Miles, 1989; NCH Scotland, 2001), additional factors have increased the complexity of the residential environment. Over the past three decades there has been a dramatic reduction in the numbers of children entering the care system (Skinner, 1992) and more recently researchers have documented the increased ratio of highly disturbed children and the increasing severity of their behaviour (Triseliotis et al., 1995; Sinclair and Gibbs, 1998). Such changes mean that staff are now working with older, more disturbed and disruptive groups of children than previous generations. Kahan (cited in Aiers and Kettle, 1998: 12) states: 'Some children in residential care at times can present behaviour which is bewildering, unpleasant, frighteningly hostile, self-destructive and undermining of all attempts at control. The confusion which gives rise to it is particularly evident in young people who have experienced placements in foster homes, children's homes, in-patient psychiatric units and secure accommodation.'

For Sinclair and Gibbs (1998: 253), four major problems prevailed within the children's homes:

1. many of the children were 'extremely unhappy or moody';

2. they behaved in 'disturbed and delinquent' ways;

3. many children lacked any integrated educational input and their long-term employment prospects were 'dismal';

4. most children came from 'disrupted families' in which high levels of conflict remained.

The impact of such negative experiences meant that despite their socially deprived backgrounds and family difficulties, the majority of children would have preferred not to be in children's homes. Sinclair and Gibbs (1998: 239) stated: 'Roughly two-thirds of each group [young people, their parents and social workers] would have preferred the young person to have remained in the community or to have been looked after somewhere other than in their current children's home.'

\section{Demands on Residential Staff}

Despite the complexities of children's homes and the central function of staff, staff are frequently overworked, underpaid, have little say in decision-making and often lack a recognized professional qualification (e.g. Baldwin, 1990; 
Skinner, 1992; Utting, 1991; Wardhaugh and Wilding, 1993; Kent, 1997). For some, residential child care has been characterized by a history of failure (CCETSW, 1992; Dobson, 1998), a situation that has not, according to Frost et al. (1999: 1), gone unnoticed by various staff groups: 'To many of those working in the system - residential carers, field social workers and managers - homes can be perceived variously as ineffective, lacking in purpose and, compared to foster and other services, very expensive to run.'

Various reports have also documented the highly stressful nature of residential environments and the risks of staff burn-out. For example, Kent (1997: 15) discussed the issue of 'poor practice in care establishments' and noted: 'Staff who were previously able and capable can be so adversely affected by low morale, depression, exhaustion or burn-out that they cease caring properly for children.' Burn-out may have a particular impact on the level of care provided in children's homes because of the centrality of the child-worker relationship. According to Maslach and Jackson (1984: 1), burn-out is a syndrome of emotional exhaustion, depersonalization and reduced personal accomplishment that can occur among individuals who do "people work" of some kind'.

Research into the concept of burn-out, although not specific to children's homes, highlights the extent to which burn-out distorts the helping relationship. Essentially, the research shows that burn-out is often characterized by workers adopting increasingly negative perceptions of clients, which can result in a process of depersonalization and dehumanization (Maslach and Pines, 1977; Maslach, 1978; Maslach, 1982; Maslach and Jackson, 1984). The link between burn-out, low morale and the nature of the working environment cannot be underestimated. Berridge and Brodie (1998) showed that staff morale was almost perfectly correlated with the quality of care in children's homes.

Although recognized as the 'really important ingredient in the care package offered to children' (Skinner, 1992: 68), few studies have focused on the perspectives of residential staff (Hicks et al., 1998). How do staff view children in these environments? More specifically, what form does the child-worker relationship take when children's needs are often unmet? Irrespective of the tasks and duties workers undertake, Hicks et al. (1998: 362) believe their work is "think-work" and it is extremely important because work is not based on the observable events themselves but on the meaning which staff members place on events, including, importantly, the young person's behaviour. If the understandings and meanings are wrong or incomplete, what follows will be faulty.'

Ascertaining the views of residential staff has, therefore, the potential to provide key insights into the nature of relationships between staff and children and hence the quality of care provided.

\section{Study Design}

The doctoral study focused on three areas: staff perceptions of Scottish Vocational Qualifications (SVQs); the residential context; and the staff's views of 
the children. The findings for the first two areas would suggest that there are serious flaws in the design and structure of SVQs (Heron and Chakrabarti, 2002a) as well as the residential contexts in which staff were assessed 'competent' (Heron and Chakrabarti, 2002b). The data presented in this article are derived from staff's perceptions of children and focus on key aspects of the child-worker relationship. As such, the article examines the interactions between staff and children and provides an insight into the experience of being in care.

\section{Interview Schedule}

Data for the study were collected from interviews with residential staff. A total of 30 staff were interviewed from seven children's homes in two different local authorities. The intention was to interview each member of staff on four separate occasions.

Data were collected from two phases of interviews separated by a period of approximately nine months. In each interview phase, workers were visited on two occasions, separated by a period of approximately three weeks. The benefit of a follow-up phase of interviews was that it allowed for two 'snapshots' of workers' experiences. Of the 120 interviews originally planned, 109 interviews were completed. The interviews were audio recorded and transcripts were analysed. The duration of interviews ranged from 50 minutes to 1 hour 45 minutes.

\section{The Repgrid}

The Role Construct Repertory Test was devised by Kelly (1955) and is based on his theory of personal constructs. Commonly referred to as the repertory grid or repgrid, it is a technique used to structure interviews. Two different repgrids were adapted to explore the perceptions staff have of children, and the residential environment. The data presented below were elicited from interviews using the first repgrid. Although there are various ways to analyse the data, this study focused primarily on the conversations generated by staff when compiling the repgrids. This is consistent with Kelly's philosophy (Phillips, 1989), that listening to what certain people say offers a unique insight into their experiences and how they view the world. It also avoids many of the flaws identified by Yorke (1985) in relation to various quantitative approaches when analysing repgrids.

The repgrid was designed to include the names of ten children (elements), three of which were derived from descriptors considered particularly significant to the client-worker relationship. The descriptors were:

1. a child you particularly care about;

2. a child who understands your role;

3. a child you find particularly challenging.

Compton and Galaway (1994) list several characteristics of the clientworker relationship. These influenced the nature of the descriptors: the first 
and third descriptors were significant because they incorporated those characteristics relating to concern, commitment, obligation, acceptance and authority. The main point for comparison, however, related to the second descriptor, a 'child who understands your role', as it conveys a sense of purpose within the relationship. Purpose is a special characteristic, according to Compton and Galaway (1994), because when it is consciously and deliberately determined and communicated in the profession's value base, it will make the social-work relationship completely different from other kinds of relationships. Purpose in the child-worker relationship could only be meaningful if the child understood what the worker was trying to achieve in terms of their involvement. In focusing on understanding there was an attempt to differentiate between involvement in a general sense and forms of involvement where the child recognized and understood the worker's actions and intentions.

The remaining seven children included as elements in the repgrid were the ones staff 'know best' or were most 'involved with'. This had a practical benefit in that it would make the elicitation of constructs easier, but it would also identify those children the worker knew well, or had more involvement with. These children provided the elements which were used, by means of triadic elicitation, to generate the constructs. The elements were then rated on a 5-point scale.

A qualitative method of data analysis was adopted: the transcripts were organized into themes and sub-themes that reflected the main issues raised by staff during the interviews. In order to convey the perceptions of staff, extracts from the transcripts have been cited along with a selection of repgrids, including an analysis of the constructs and ratings.

The data are presented in the form of a case study of a children's home. It is a summary of one of three case studies presented in the doctoral study. A selection of data from the other case studies is also included to highlight common issues. The rationale for using a case study is documented by Cohen and Manion (1997: 106): "to probe deeply and to analyse intensively the multifarious phenomena that constitute the life cycle of the unit with a view to establishing generalizations about the wider population to which that unit belongs'.

This rationale is conducive to the methodology of the study because the repgrid has the potential to generate highly detailed insights into the staff's experiences. Utilising a case study approach to organize these insights highlights many of the complexities of life in children's homes and the dominant factors that shape the quality of relationships between children and staff.

The size of the children's homes varied between 6 and 12 children with staff groups ranging from 23 (including cooks and cleaners) to 12. The children's homes were rarely without their full complement of children. When conducting the interviews one or two children appeared to dominate staff's conversations in each of the children's homes. 


\section{Case Study: Phase 1}

Frank ${ }^{1}$ was 15 years old and had recently been moved to a residential school because of allegations about him sexually abusing another boy in the children's home. The main issues raised by staff about Frank were:

- his alleged sexual abuse of a nine-year-old boy in the children's home;

- the uncertainty of some staff over the way the incident was dealt with by management;

- not initially informing his mother although he had been returned home on a temporary basis to live with his siblings;

- uncertainty about interviewing the child and 'contaminating the evidence';

- feeling excluded from the decisions being made;

- the lack of resources and belief that moving him to a residential school would not meet his needs.

Despite their concerns, the staff did not appear to have expressed them to their manager. Generally, there was an acceptance they would not be listened to and any conversations with the unit manager were aimed at protecting staff's own backs, rather than believing their opinions would shape any decisionmaking. Of course, it could be argued that in such situations, it is necessary to make quick decisions based on limited information, some of which staff may not be privy to. However, issues relating to the staff's sense of powerlessness are not linked solely to the incident. Events leading up to the alleged assault raise fundamental questions about the ability of staff to protect certain children.

\section{A Child Who Avoids Staff}

Before the incident that resulted in Frank's removal from the children's home, it would appear that he had minimal involvement or attention from staff. Of the seven repgrids compiled by staff, five included Frank as one of the 'elements'. This would suggest that staff knew him and/or had some involvement with him. The two workers who did not include Frank in their repgrid probably did not know him particularly well or did not have much involvement with him. One worker identified Frank as a 'child you particularly care about' (element 1). Two workers selected Frank as a 'child you find particularly challenging' (element 3). It should be noted that one of these workers completed the repgrid after the alleged incident of sexual abuse occurred, and this may have been an factor influencing their decision to place Frank in this category. None of the workers identified Frank as the 'child who understands your role'. This would suggest that although workers had involvement with him or knew him, he was not a child who, compared with his peers, understood the purpose of their work.

Before the incident occurred all seven workers spoke about various children when compiling the repgrid; however, only one made a direct reference to Frank. In contrast, after the incident, he was the focus of most conversations. 
Comments from staff would infer that they believed the abuse had been occurring for some time. Their views had been consolidated by information given by Frank after the incident. Yet the one and only comment made in specific reference to Frank before the incident was that he 'just takes what's given. It's a shame, sometimes he doesn't get his fair share because he's not pushy like the others. We sometimes forget about him, because he's not so demanding.'

This comment suggests quite strongly that the worker is aware of the inadequate attention given to Frank. The primary reason that he is not so demanding', would seem to refer not specifically to his level of needs, but from the fact that 'he's not pushy like the others'. This worker's repgrid provides an insight into how he perceives Frank.

Despite this worker's admission that Frank did not get his 'fair share', he was perceived as a child in 'need of attention' (c 2), ${ }^{2}$ and who exhibited 'aggressive/abusive' behaviour (c 5). It is unlikely that his needs were being fully met by his family, who had 'regular family contact' (c 8), although he did 'not live with siblings' (c 3) and the 'relationship (with his mother) needs work' (c 4). As Frank had a 'long experience of care' (c 6), it was difficult to foresee how his relationship with his mother was likely to improve without any significant increase in the staff's involvement. Given these factors, it is perhaps not

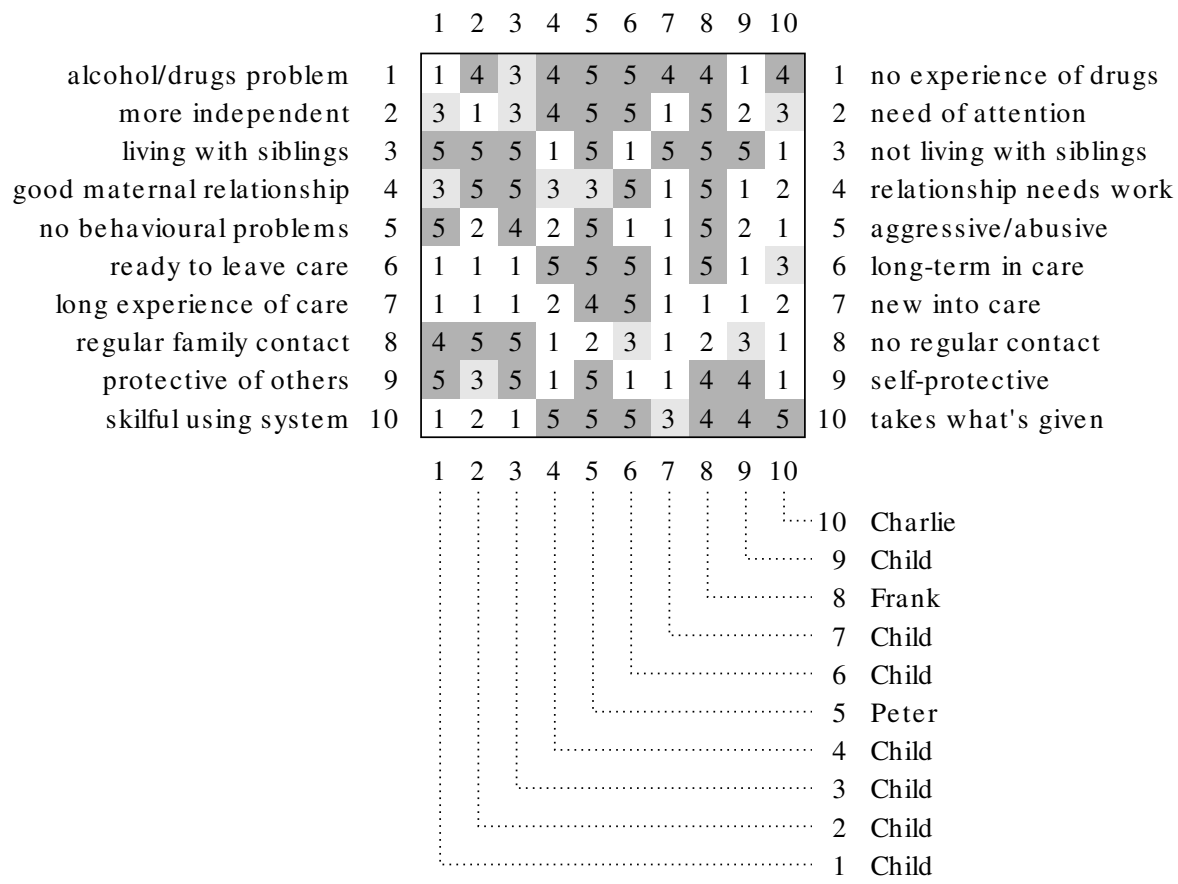

Figure 1 Display of the children repgrid from the first phase of interviews 
surprising that Frank was 'self-protective' (c 9). Although Frank 'takes what's given' (c 10), with the benefit of hindsight, he might have been more 'skilful using [the] system' than this worker initially believed. As previously noted, several staff believed that the abuse had not been a one-off incident. In the lead-up to the incident, which resulted in the allegations of sexual abuse, Frank may have in fact been quite skilled in not bringing attention to himself, hence the view that staff 'forget about him'.

From an examination of the workers' constructs, Frank did not appear to have anything very positive in his life, and he had little involvement from staff. Moreover, the worker highlighted above was aware of his lack of involvement with Frank. Other staff appear to have adopted a similar ambivalence. Although it is impossible to know why Frank abused another child (assuming the allegations are accurate), the lack of involvement from staff may be a crucial factor in creating a more risky environment, thus facilitating the abuse and implying that the ability of staff to protect children might be minimal.

\section{Apathy of Staff tow ards Some High-Risk Situations}

Even when there were concerns about a child's abusive behaviour, the potential for staff to do any preventative work was quite limited. For example, in another children's home some of the staff expressed concerns about Charlie, who was displaying inappropriate sexual behaviour towards some of the younger children. 'It's really disturbing. He's never out of the wee boys' room. We've got concerns about what he's up to with them. Real concerns. We really need to tag him. It's a shame, he's a dead vulnerable wee boy and he's really struggling, but he's just really difficult to work with.'

Despite staff's concerns, there appeared to be some apathy towards providing adequate protection for the other children. Another worker, when discussing Charlie, stated:

He's only 12 but he's a real problem. He's had so many difficulties before he came into care. He's not opened up yet. His mother had a drink problem and he had loads of step-fathers. We're getting a psychologist to assess him soon. We're really worried, he's constantly around some of the younger kids and we think it may be a sexual thing. But you can't watch him all the time. There's not enough staff, but it's a real worry.

Although an appointment had been made with a psychologist, the risks to other children might be exacerbated by additional factors:

The behaviour of the kids is really bad, but that just reflects the disorganised staff team. We don't know if we're coming or going. There's no consistency. The deputy and the manager have very different ideas. One says one thing and the other tells you something else. Staff are really fed up. We've had a lot of sick leave over the past few months. What else can you do when it gets so bad.

Therefore, even when staff had real concerns about a child's abusive behaviour, as evident from the situation in this other children's home, they felt quite powerless to do anything about it. 


\section{Being the Focus of Staff's Attention}

Although Frank dominated much of the staff's conversations after the incident, another child, Peter, appeared to preoccupy their thoughts beforehand. The repgrid shown in Figure 1 shows the similarities between Peter and Frank. Peter was perceived as 'aggressive/abusive' (c 5) who was in 'need of attention' (c 2) and who had a 'long experience of care' (c 7). Peter's relationship with his mother was rated ' 3 ' on the construct (c 4) 'good maternal relationship relationship needs work' and he was 'not living with siblings' (c 3). In terms of the future, Peter was likely to be 'long-term in care' (c 6), remains 'self-protective' (c 9) and 'takes what's given'.

Comments about Peter tended to focus on his behaviour. For example, a worker stated: 'Behaviour wise is a big factor. He's very aggressive and abusive.'

The following comments give some explanation as to why his behaviour was so problematic:

Peter is verbally abusive. He won't take a telling. He's got too much anger and aggression because of all the problems he's dealing with. He's so wound up, and everything is so above his head that it comes to the point where he's got to be restrained. He doesn't have the ability to listen to what other people are saying and it ends up in a physical restraint. He recently built up contact with his mum, but she died, so he's got the whole bereavement to deal with. That's why his behaviour is so bad just now.

Another worker stated: 'His mother died a few months ago. To make matters worse there are kids in here from the same area and they're winding him up about it. They don't do it in front of staff ... You can't catch them, but we know they are doing it. Certainly, he had behavioural problems before, but this isn't helping.'

There would appear to be very obvious reasons for Peter's problematic behaviour. However, not all workers seemed to share the same level of understanding about the link between previous events and his present behaviour. One worker, when commenting on Peter and another child, said: 'They do not think of the wider group. They are very selfish.'

It is impossible to know exactly what 'very selfish' means for this worker, given that the child's mother had recently died and the other children are 'winding him up about it'. To examine this issue further, it is useful to consider this worker's repgrid.

Peter was identified by this worker as a child he found 'particularly challenging' (element 3). He was perceived as a child who was 'verbally aggressive' (c 3), 'selfish to others' (c 9) and 'immature' (c 7). Not only did his behaviour present problems, Peter might be particularly demanding for staff given that he did 'not accept care' (c 2), did not 'accept[s] negative decisions' (c 6), and 'seeks [the] pecking order' (c 8). Peter might present serious difficulties for all staff, but particular problems for this individual. The worker's constructs focused primarily on behaviour. Essentially, it would seem that they related to the extent to which children were willing to accept authority and control, as suggested by the 
constructs: 'verbally aggressive - quiet/withdrawn'; 'doesn't abscond - absconds'; 'accepts negative decisions - seeks positive decisions'; 'immature - mature'; 'seeks pecking order - rejects pecking order'; 'selfish to others - understanding to others'. Such constructs refer to the behaviour of these children in the immediate surroundings of the home. No mention was made of factors such as family relations or siblings; similarly, there was no notion of past or future. They were located very much in the present, and related to things that affected the worker within the children's home. The dominance of the present in this worker's constructs may explain why the child, whose mother had died a few months earlier, was seen as 'selfish'. Perhaps more importantly, it questions the degree to which this worker was able to protect the children from abuse. Given the complexity of residential care and the difficulties in collating evidence to support allegations of abuse, it is not clear how a worker with such an understanding could contribute meaningfully towards creating a protective environment.

Although the first phase of this case study has highlighted the dominance of Frank and Peter in the conversations of staff, many of the issues raised are not unique to these two children. The quality of care in general was criticized by staff, as noted by the following comment: 'Really no work is done in here. They could get Group 4 to do it. It's sheer containment. At times we're

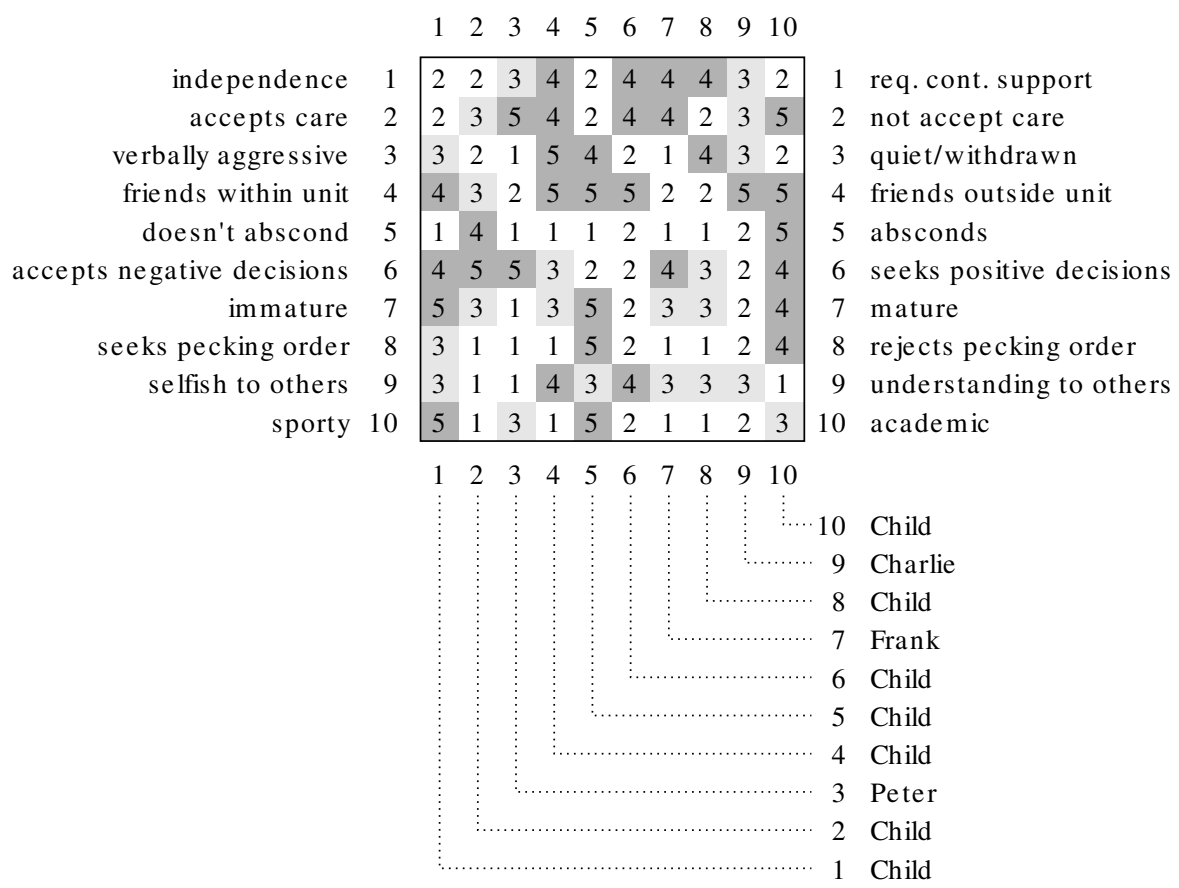

Figure 2 Display of the children repgrid from the first phase of interviews 
turnkeys, prison officers. We don't do any positive work with children. It's so sad, they deserve better. This place is too big, too many children.'

The inability of staff to meet the needs of the majority of children was a recurring theme in all of the case studies.

\section{Case Study: Phase 2}

Peter remained the focus of many staff's conversations during the second phase of interviews. However, unlike Frank, several staff believed moving Peter to a residential school would be a positive strategy. Although staff often referred to Peter's disruptive behaviour, their sense of powerlessness was also conveyed:

That boy you can hear just now, he's only 12. Listen to him [swearing]. That's constant ... And there's nothing we can do. We don't have the time to do any work with any of the kids on an individual basis. They come in here and we don't deal with their problems. You know, the reason they come in here. What usually happens is they just get worse. It's bums on beds. We've no resources to do anything. All we're doing is containing the kids. It's really sad, although we're not too bad in here just now.

The main preoccupations of staff's conversations about Peter were:

- the level of his verbal and physical abuse towards staff;

- the lack of educational input; he was scheduled to attend a specialist school for only eight hours per week, but he often refused to go;

- $\quad$ his needs were not being adequately met.

Of the seven workers interviewed, six included Peter in their repgrid. This suggests that only one worker did not know Peter particularly well or had a low level of involvement with him. One worker identified Peter as 'a child you particularly care about' (element 1). No worker selected Peter as 'a child who understands your role'. This infers that although staff had involvement with him or knew him, he was not a child who, compared with his peers, understood the purpose of their work. Three workers selected Peter as a child they found 'particularly challenging' (element 3 ). What they appeared to find particularly challenging was Peter's disruptive behaviour and his extreme verbal and physical abuse.

When examining the repgrids, there were certain common issues. The staff who included Peter in their repgrid identified him as being 'isolated' within the children's home. The repgrid of the one member of staff who identified Peter as 'a child you particularly care about' (element 1) highlighted his vulnerability and isolation. This worker's first repgrid was highlighted in the first phase (the first repgrid displayed) of the case study. The second repgrid allowed for comparisons of his perceptions of Peter to be examined.

The worker perceived Peter as 'alone in [the] unit' (c 1), which refers to the fact that he had no siblings in the children's home. Although Peter 'wants closeness with parents' (c 8) he 'needs more family contact' (c 10). The isolation from 
his family was mirrored by his limited interactions with significant others, for example, he did 'not attend mainstream school' (c 3) and had 'no outside interests' (c 6). Spending so much time in the unit might explain to some extent why he was so 'aggressive' (c 7). The lack of structure and stimulation in his everyday life might be a significant factor in his disruptive behaviour. Of particular concern in terms of his isolation, is that he was a 'victim of bullying' (c 5). If Peter were being bullied, then who could he get support from when he was isolated in the children's home and when he had no contact with any significant adults outside it?

On examining Peter's situation, it was highlighted in phase one that he dominated much of staff's conversations until the incident with Frank emerged. After Frank was moved out of the children's home, Peter re-emerged as the focus of staff's conversations. Comparisons between both repgrids from the same worker highlight the abusive nature of his behaviour. What might be of particular significance is the link between the inability of staff to meet his needs and the continuing deterioration in his quality of life.

It seems crucial, especially during such a transitory period (i.e. being moved from the children's home to a residential school), that attempts to develop the child's understanding of his situation would be a priority. None of the comments

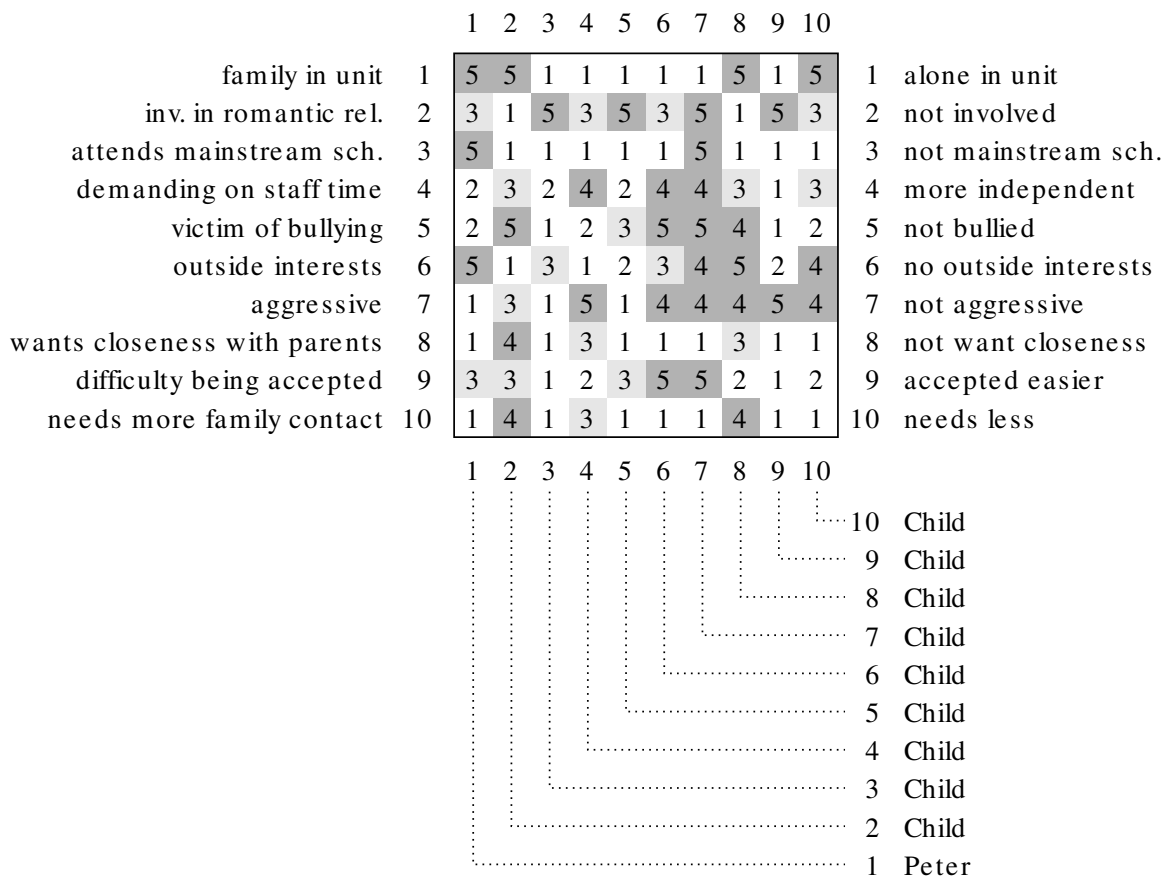

Figure 3 Display of the children repgrid from the second phase of interviews 
by staff suggest this was the case. Despite dominating so much of staff's conversations in the first and second phase of interviews, Peter was not identified by any worker as 'a child who understands your role'. Given his isolation, level of understanding of staff and the fact that he was being bullied, it is difficult to appreciate how this child would experience the transition to another residential environment.

\section{Discussion}

There are considerable differences between children's homes in terms of, for example, their culture, size and ethos. Consequently, attempts to make any generalizations, especially from a small-scale study, should be treated with caution. Nevertheless, the deficiencies highlighted in the case study suggest they cannot be viewed as separate or isolated events. Moreover, many of the issues discussed are not new and have been well documented (Frost et al., 1999).

The lack of support, inadequate resources, and minimal feedback and supervision in certain children's homes (Heron and Chakrabarti, 2002b) may represent an undercurrent to the lack of involvement with some children. Though all the children are vulnerable, the significance of those in the case study is that they dominated much of staff's conversations. The main point is that if staff do not have sufficient levels of involvement with all of the children, then it will undermine their ability to create a safe and caring environment.

\section{Powerlessness and the Child-Worker Relationship}

When staff feel quite powerless then not only are they working in an oppressive environment, it questions how they can influence a service aimed at meeting the children's needs. As Dominelli (1997: 6) points out: 'Power is at the heart of the definitional process'. In the struggles that exist between staff and children, a powerless staff group may be unable to define the true nature of children's needs. The structured inequalities of residential child care, most notably in terms of its residualization and failure to educate and professionalize staff, have been an enduring feature. If staff had the power to define the realities of children's homes, would they want a system that does not meet the children's needs? For some children in the study, their right was to be placed in an environment where they could not be adequately protected. Such rights only exist in a shallow and tokenistic legal system. Without an empowered staff group, the children cannot be empowered, leaving both parties denied meaningful rights within an oppressive and neglectful care system.

\section{Burn-out, Coping Strategies and Control}

The withdrawal of the staff's involvement from the children may in some instances be symptomatic of burn-out. Kent (1997), as noted previously, suggested that burn-out is not uncommon in residential child care. The combination of excessive stress, violence, inadequate support and being unable to 
meet the children's needs may create a situation in which staff withdraw their involvement, especially from certain children. Although the avoidance strategies or low levels of involvement with children cannot be considered good practice, it should not necessarily be interpreted as a lack of commitment from staff. Given the extreme violence and disruptive behaviour displayed by certain children, the withdrawal of staff by, for example, staying in the office, may reflect a form of coping, especially when a children's home is out of control. Irrespective of any such rationale, it is clearly not a desired situation.

Increasing opportunities for staff to be involved meaningfully in children's lives may require a radical shift in the way control is wielded in social work departments. The increasing level of control by employers has, according to Jones (1999: 47), contributed to 'a fundamental shift of focus in British state social work, in which the needs and demands of the agencies - rather than those of the clients - are given primary consideration'. In failing to meet their needs, many children are a product of the children's homes, a consequence of staff being unable to care for them. Issues of care and control are inextricably linked, therefore staff will only be able to provide adequate care when employers relinquish some of the control they have used to prioritize the needs of agencies over children.

\section{An Alternative to Children's Homes}

The disempowered position of staff is embedded in the everyday working practices of the children's homes. This situation stems from a misguided premise that the best interests of a child can be met in a residential establishment. There was little evidence in this study to support the view that living in a children's home was a positive choice. Instead, it was one of containment, often characterized by an 'us' and 'them' mentality. These findings are of course not new. For example, Utting's (1997: 11) review of safeguards in England raised fundamental questions about the ongoing nature of residential care and the working practices of staff: 'Information has since come to light ... about serious and systematic abuse of children in children's homes over a period of many years ... It therefore becomes necessary to ask whether the safeguards instituted since 1991 are strong enough to prevent similar abuses occurring.'

Placing a child who has extreme emotional difficulties and/or behavioural problems with a group of children with similar problems is the essence of residential care. This mix of children, with so many staff, is the root cause of the failings of residential care. Irrespective of resources, philosophy, education and training within the current paradigm, the failings will continue because they are a response to the nature of residential care, rather than the needs of the individual children. To place a 'normal' child with a healthy and stable background in a children's home would probably be extremely detrimental to his or her emotional well-being. Why then, are some of the most disadvantaged children placed in such environments? If most adults who were considered good parents would find it difficult to care for one child who might otherwise be admitted to 
a children's home, then caring for two such children in one family home could be even more demanding. Given the lack of suitable foster placements and the inappropriateness of this service for some children (Barry, 2001) and the continuing failure of residential care, there is a need for an alternative approach. If the reality is to match the government's rhetoric, then family-type living environments must be established for each individual child or sibling group to be accommodated. Such a proposal may appear somewhat idealistic or even unrealistic. However, it should be remembered that the current system is not meeting the needs of many children. These new environments would give children a genuine opportunity to deal with the difficulties which resulted in them being removed from their own homes. In doing so, their development would not be hindered by the tension, conflict and chaos so often characteristic of the children's homes in this study.

\section{Sustaining the Status Quo}

Creating alternative family environments using professional workers would not only end the tradition of children's homes, it would also do away with workers' requirement of a residential qualification. A new residential child care pathway is being offered by the Scottish Institute for Residential Child Care (SIRCC) as part of the DipSW/BA programme. Although this qualification may enhance the status and pay of some staff, its overall impact may be limited without substantial changes in the residential system. Firstly, there are major barriers in accessing such a course. Low educational attainment and lack of confidence in this sector, combined with inadequate funding to release staff from the workplace, question the extent to which this qualification is genuinely accessible. So there is a likelihood of an elite emerging like the 'super-teacher' category in schools. Secondly, the report by Kent and Payne (2000) on the Residential Child Care Initiative (RCCI) in England suggests that qualifying staff to DipSW level without a radical restructuring of the residential environments has minimal impact on practice.

It is also difficult to foresee how plans to introduce an honours degree in social work in 2004 can meaningfully coexist with the newly created Scottish Social Services Council's (SSSC) recommendation that residential child care staff be qualified at level 2 of Scottish Vocational Qualifications. Instead of devising and attempting to justify new residential qualifications, it is necessary to give those staff who provide the direct care to children equity with social workers. Wouldn't an honours degree that provided knowledge and skills in teaching and parenting, which were linked to academic subjects such as psychology and sociology, be as valuable to residential child care staff as it was to field workers? This approach would be more in alignment with the Social Pedagogue or 'Educateur' programmes that have a duration of three or four years in some other European countries (Crimmens, 1998). Highly qualified staff with individual children, or sibling groups, in an environment that could replicate the best features of family life would enable children to make sense 
of their disadvantage, understand the role of their carers, and thrive rather than be contained.

Creating these family-type environments would reflect a very different approach to caring for some of the most vulnerable children in society. Reasons to reject the thrust of these suggestions and maintain the status quo are numerous. Perhaps the decision to continue with a residential system that does not meet the needs of children and augment it with vocational qualifications is not so surprising. After all, as Chomsky (1993: 75) reminds us: 'Nothing is easier than to convince oneself of the merits of actions and policies that serve selfinterest. Expressions of benevolent intent, in particular, must be regarded with much caution: they can be taken seriously when policies advocated happen to be harmful to self-interest, a historical category that is vanishingly small.'

\section{Conclusion}

The evidence in this study suggests that the low level of staff involvement with certain children reflects the disempowered position of staff. Without feeling safe and protected, any notions of equality can have little genuine meaning to some of the children in this case study. Though the children discussed might be unrepresentative in that they were particularly vulnerable and demanding, they were in many respects a product of the children's homes, a consequence of staff being unable to care for them and meet their needs. As the failings of residential child care continue into the 21 st century, it is time to question the function of children's homes and give consideration to alternative environments that will genuinely meet the needs of some of the most vulnerable children in society.

\section{Notes}

1. All names in the text have been changed to protect the confidentiality of staff and children.

2. The information in brackets refers to the construct number in the repgrid. So, for example, (c 2) refers to the second construct in the repgrid.

\section{References}

Aiers, A. and Kettle, J. (1998) When Things Go Wrong: Young People's Experience of Getting A ccess to the Complaints Procedure in Residential Care. National Institute for Social Work. Derby: Meridian.

Baldwin, N. (1990) The Power to Care in Children's Homes. Aldershot: Avebury.

Barry, M. (2001) A Sense of Purpose. Care Leavers'Views and Experiences of Growing $U p$. Edinburgh: Save the Children Fund.

Bebbington, A. and Miles, J. (1989) 'The Background of Children who Enter Local Authority Care', B ritish Journal of Social Work 19: 349-68.

Berridge, D. and Brodie, I. (1998) Children's Homes Revisited. London: Jessica Kingsley.

Central Council for Education and Training in Social Work (CCETSW) (1992) Setting Quality Standards for Residential Child Care: A Practical Way Forward. London: CCETSW. 
Chomsky, N. (1993) Year 501, The Conquest Continues. South End: Verso.

Cohen, L. and Manion, L. (1997) Research Methods in Education, 4th edn. London: Routledge.

Compton, B. and Galaway, B. (1994) Social Work Processes. Belmont, CA: Brooks/Cole.

Crimmens, D. (1998) 'Training for Residential Child Care Workers in Europe: Comparing Approaches in the Netherlands, Ireland and the United Kingdom', Social Work Education 17(3): 309-20.

Dobson, F. (1998) The Government's Response to the Children's Safeguards Review, Foreword. London: The Stationery Office.

Dominelli, L. (1997) Sociology for Social Work. London: MacMillan Press.

Frost, N., Mills, S. and Stein, M. (1999) Understanding Residential Child Care. Aldershot: A shgate.

Heron, G. and Chakrabarti, M. (2002a) 'Impact of Scottish Vocational Qualifications on Residential Child Care: Have They Fulfilled the Promise?', Social Work Education 21(2): 183-97.

Heron, G. and Chakrabarti, M. (2002b) 'Examining the Perceptions and Attitudes of Staff Working in Community Based Children's Homes: Are Their Needs Being Met?', Qualitative Social Work 1(3): 341-58.

Hicks, L., Archer, L. and Whitaker, D. (1998) 'The Prevailing Cultures and Staff Dynamics in Children's Homes: Implications for Training', Social Work Education 17(3): 361-73.

Jones, C. (1999) 'Social Work: Regulation and Managerialism', in M. Exworthy and S. Halford (eds) Professionals and the New Managerialism in the Public Sector. Buckingham: Open University Press.

Kelly, G. A. (1955) The Psychology of Personal Constructs. New York: Norton.

Kent, J. and Payne, C. (2000) 'A fter the Residential Child Care Initiative: What Next?', report of a follow-up study of students who completed the De Montfort University Diploma in Social Work 1992-7. London: National Institute for Social Work.

Kent, R. (1997) Children's Safeguards Review. Social Work Services Inspectorate, Edinburgh: The Scottish Office.

Maslach, C. (1978) 'The Client Role in Staff Burn-Out', Journal of Social Issues 34(4): $111-24$.

Maslach, C. (1982) Burnout: The Cost of Caring. Englewood Cliffs, NJ: Prentice-Hall.

Maslach, C. and Jackson, S. E. (1984) 'Burnout in Organizational Settings', in S. Oskamp (ed.) A pplied Social Psychology, Annual 5. Beverly Hills, CA: Sage.

Maslach, C and Pines, A. (1977) 'The Burnout Syndrome in the Day Care Setting', Child Care Quarterly 6: 100-13.

NCH Scotland (2001) Factfile. Facts and Figures A bout Scotland's Children. London: $\mathrm{NCH}$.

Phillips, E. M. (1989) 'U se and Abuse of the Repgrid: A PCP Approach', The Psychologist: Bulletin of the British Psychological Society 5: 194-8.

Sinclair, I. and Gibbs, I. (1998) Children's Homes. Chichester: Wiley.

Skinner, A. (1992) A nother Kind of Home: A Review of Residential Child Care. Edinburgh: HMSO.

Triseliotis, J., Borland, M., Hill, M. and Lambert, L. (1995) Teenagers and the Social Work Services. HMSO.

Utting, W. (1991) Children in Public Care: A Review of Residential Care. London: HMSO. 
Utting, W. (1997) People Like Us: The Report of the Review of the Safeguards for Children Living A way from Home. London: HMSO.

Wardaugh, J. and Wilding, P. (1993) 'Towards an Explanation of the Corruption of Care', Critical Social Policy 37: 4-31.

Yorke, D. M. (1985) 'Administration, Analysis and Assumption: Some Aspects of Validity', in N. Beail (ed.) Repgrid Technique and Personal Construct: A pplications in Clinical and Educational Settings. London: Croom Helm. 